\title{
Crowd Logistics' Impact on Environmental Sustainability in a Developing Economy: An Analysis in Ghana
}

\author{
Abdul-Hamid Zalia ${ }^{*}{ }^{\circledR}$, Yi Zhang1, Abubakar Aishatu2 ${ }^{\circledR}$, Adzani Sophia Akosua1, \\ Baba Vanessa Fathia1 \\ ${ }^{1}$ College of Economics and Management, Taiyuan University of Technology, Taiyuan, China \\ ${ }^{2}$ School of International Education, Jiangsu University of Technology, Changzhou, China \\ Email: `zaliaabdulhamid96@gmail.com,370446731@qq.com, yishabuba@gmail.com, sophiaadzani@ymail.com, \\ vanessafathia@gmail.com
}

How to cite this paper: Zalia, A.-H., Zhang Y., Aishatu, A., Akosua, A. S., \& Fathia, B. V. (2021). Crowd Logistics' Impact on Environmental Sustainability in a Developing Economy: An Analysis in Ghana. American Journal of Industrial and Business Management, 11, 416-436.

https://doi.org/10.4236/ajibm.2021.115027

Received: March 29, 2021

Accepted: May 15, 2021

Published: May 18, 2021

Copyright (c) 2021 by author(s) and Scientific Research Publishing Inc. This work is licensed under the Creative Commons Attribution International License (CC BY 4.0).

http://creativecommons.org/licenses/by/4.0/

\begin{abstract}
Purpose: With the recent emergence of crowd logistics as a form of delivery that involves ordinary citizens rather than skilled couriers, understanding its environmental impact has become an area of concern in most researches. The concept behind crowd logistics is to make use of empty spaces of private individuals who are on an intended trip. The use of empty spaces decreases the number of empty kilometers on the road, lowering emissions and it's thought to ensure environmental sustainability. This article presents the analysis of crowd logistics from an environmental sustainability perspective with much focus on the crowd's behavior. Methods: Survey data from 222 respondents representing various stakeholders was analyzed using IBM SPSS version 25.0 software and IBM AMOS version 24.0 for Structural Equation Modelling (SEM) analysis to delve deeper into crowd logistics' environmental effects. Findings: The findings indicate crowd logistics positively impacts the environment but efficient participation of the crowd is critical in achieving that. Implication: Our findings complement existing literature by providing insight on the role of the crowd in the practice of crowd logistics to achieve environmental sustainability. Policymakers can use this to make policies that ensure efficient transport behavior from the crowd in order to achieve environmental sustainability.
\end{abstract}

\section{Keywords}

Crowd Logistics, Urban Freight Transport, Sustainability, Crowd Workers, Motivational Factors 


\section{Introduction}

The production process is not really complete until the goods/products are delivered to the final consumer. As a result, logistics transportation is a vital component of logistics. The significance of logistics, according to (Esmizadeh \& Mellat Parast, 2021), is the movement of products from their manufacturing location to the final consumer. The majority of logistics services' operations revolve around transportation (Islam et al., 2013). Transportation, also, is considered to have the greatest environmental impact of all logistics activities. Hence the practice of efficient logistics transport is part of ensuring the sustainability of the environment and society.

Despite the positive impact on economic growth and development, the repercussions of logistics transport on the society ought not to be ignored. According to (Rześny-Cieplińska \& Szmelter-Jarosz, 2019), traffic and congestion are always the most critical issues that need attention in order to improve urban movement among all the negative effects of transportation. Logistics transport drivers mostly park in the second lane, blocking pedestrian sideways and generating unwanted impediments and congested roads (Herrmann \& Kunze, 2019). Freight transport has also been known for numerous pollutions on the environment and its consequent health implications. Among some of the negative impacts of freight transport are climate damage, air pollution, noise pollution and physical waste. Solutions that are climate friendly have become a necessary demand specifically in the field of logistics transportation (El-Berishy et al., 2013).

Several measures and innovative ideas have been brought up to curb these consequences. By optimizing the architecture of a logistic network, utilizing the right mode of transportation, and managing load capacities and routes effectively, substantial reductions in carbon emissions and transportation costs are now feasible (El-Berishy et al., 2013). The Internet has brought about new many new ways of sharing Belk 2013 of which logistics transport isn't excluded. Crowd logistics is a sustainable concept introduced to make delivery process of logistics easier and faster. The practice of the concept reduces the number of freight vehicles in the society. This idea of logistics delivery is hinged on network of connected people that use their free time and/or empty space to help deliver goods to other people in return for financial benefit (Jeremic \& Andrejic, 2019). Crowd logistics (CL) delivery services take advantage of passengers' spare capacity on already-completed journeys, contributing to economic, social, and ecological impact (Rai et al., 2017). The business model is premised on the reality that many vehicle drivers with unused cargo capacity are on their way every day (Mladenow et al., 2016). It creates an incentive for people who want to be committed to distribution to build their own flexible work (Rougès \& Montreuil, 2014). The term "crowd" in crowd logistics refers to a wide network of independent people who are participating voluntarily (Sampaio et al., 2019). The reduction of vehicles in the society which subsequently leads to reduction in pollution in the environment is the sustainability part of the concept. 
Meanwhile, digitization is the foundation of crowd logistics as the platform has to be online for customers to find and make decisions. The rise of crowd practices is based on the concept that people have capacity that can be used to conduct traditional business operations via IT platforms (Carbone et al., 2017). Crowd logistics is a form of crowd sharing as the task of logistics delivery which was before carried out by traditional logistics drivers is now shared with the crowd. While the idea of crowd sharing is not fresh, the recent development in the shared mobility is due to advances in information and communication technology (Szmelter-Jarosz \& Rześny-Cieplińska, 2020).

Crowd logistics has been significant in current research studies especially in the field of logistics transportation yet limited work has been done by researchers especially on the crowd logistics' effect on the environment. According to (Rai et al., 2018), Just a few studies and research are devoted to the subject of crowd logistics. From a practical standpoint, some initial insights and understandings have already been obtained, but theoretical research on Crowd Logistics is still in infant stages, and some research questions remain unanswered (Mehmann et al., 2015). Knowledge on business models, tactics and vision of the future of the industry is scant (Rougès \& Montreuil, 2014). Several crowd logistics projects are still in the early stages of growth, while others have collapsed, and new ones are continually developing. It can be difficult to find a diverse range of initiatives to examine (Carbone et al., 2017).

The study's objectives are grouped into three categories: 1) to assess the stage of crowd logistics in Ghana, 2) to assess crowd's transport behavior and 3) to analyze the impact of crowd logistics on environmental sustainability. This study helps to enhance our understanding on the impact of crowd logistics on environmental sustainability. It also aims to add to the growing literature on crowd logistics by presenting information from the West African perspective.

The study is divided into five parts. The introduction is presented in the first section of this article. Section two reviews the related literature on crowd logistics specifically on the rise of the concept, crowd's transport behavior and factors influencing crowd's participation, and the impact of the concept on environmental sustainability. Section three describes the methodological approach to this study. Section four presents the research result and analysis. Section five discusses findings and explains conclusions.

\section{Literature Review}

\subsection{Concept Overview}

The idea from which crowd logistics emerged is crowd sourcing (Odongo, 2018). Crowd Sourcing is a neologism of the words "crowd" and "outsourcing" (Howe, 2008), whereby "crowd" is defined as a mass of people and the shift of processes, functions and responsibilities to third parties is described by "outsourcing". Crowd logistics is known as the application of the principle of crowd sourcing in logistics (Jeremic \& Andrejic, 2019). 
Mehmann et al. (2015) gave a definition for Crowd logistics which states that "Crowd Logistics designates the outsourcing of logistics services to a mass of actors, whereby the coordination is supported by a technical infrastructure. The aim of Crowd Logistics is to achieve economic benefits for all stake- and shareholders." Crowd logistics which is also referred to as crowdshipping, crowdsourced delivery, cargohitching or collaborative logistics, is presented as a promising idea that allows travelers to use their spare carrying capacity to hold packages for other people (Carbone et al., 2017). Crowd logistics initiatives can be considered as new entrants in the logistics service industry and they may represent a threat that traditional LSPs should consider (Carbone et al., 2017). In a way, $\mathrm{CL}$ can be considered disruptive in the conventional logistics industry (Rai et al., 2017).

According to Carbone et al. (2017) "Crowd logistics is done through collaborative platforms and mobile apps that connect individuals and firms to peers (travelers, movers, authorized drivers, owners of empty storage spaces, etc.) in order to make the best use of distributed, idle logistics resources and capabilities". Smartphone applications and Internet networks are the information systems for crowd logistics (Carbone et al., 2017). Currently, Uber and Airbnb have shown that online networks can be used to coordinate private asset access (Odongo, 2018).

Basically, Crowd Logistics companies act as mediators that link volunteer drivers to logistics suppliers and receivers who are already on a scheduled journey. The mediator is responsible for collaboration and therefore primarily provides an IT platform capable of communications monitoring, master data management and payment transaction performance (Mehmann et al., 2015). Logistics is certainly one of the fields where IT has had a significant impact. There, a company provides the technical infrastructure and each individual may act as both a client and a supplier (Mladenow et al., 2015). The framework searches for matchings of crowdsourcers and crowdsourcees after both requests are stored, and then the application allows them to create correspondence on the price, the pickup/delivery address and the contact information in a target-oriented manner (Mladenow et al., 2016). In this regard, the main factor is the digitization of society (Mehmann et al., 2015). The concept is based on physical internet because technology allows passengers to use the extra space in their vehicle more efficiently, by carrying and delivering items to others (Rai et al., 2017).

\subsection{Crowd Logistics in Ghana}

Ghana's freight transportation is rising at an unprecedented pace as the country's economy and foreign trade develop (Ansah et al., 2020). This increase culminated with an increase in the environmental risks associated with freight transportation. The standard of the urban atmosphere has deteriorated due to noise and emissions from vehicles (Obeng-Odoom, 2010). Owing to a shortage of on-road and off-road parking spaces for freight trucks in Ghana, they are forced to park in illegal locations, which adds to traffic congestion (Sarbah et al., 
2014). Creative alternative solutions are needed to address Ghana's transportation issues. Many alternatives to control the number of private vehicles are proposed (Armah et al., 2010). In order to achieve this, a travel demand management system needs to be set up in order to contain the potential increasing number of cars (Armah et al., 2010). Firms in African markets are increasingly gaining access to new information technology including the Internet and mobile technology (Dadzie et al., 2015). The practice of the concept of crowd logistics indirectly existed in Ghana as one out of ten of passengers and drivers has willingly delivered goods/parcels to someone at their destination. A few logistics Tech firms are rising in Ghana creating platforms for stakeholders to easily connect, deliver and receive goods. Despite the recent emergence of the concept in Ghana, not enough research has been done on the topic by researchers for the Government and other stakeholders to make use of it. There were no related relevant research papers found after a thorough review of the term "crowd logistics in Ghana". One competitive strategy that holds promise for Africa's emerging markets, but has received relatively no systematic empirical investigation, is integration of the supply chain itself with marketing channels and logistics management practices (Dadzie et al., 2015). Failure to understand logistics as a distinct strategic function within the Ghanaian Freight system is a big challenge to the growth of the system (Ansah et al., 2020).

\subsection{Crowd's Transport Behavior}

The crowd is at the forefront of all stakeholders in crowd logistics (Rai et al., 2017). The most significant element of the platform provider is the crowd (Rai et al., 2018). According to Carbone et al. (2017), ordinary individuals can take on some logistics tasks, play an unprecedented and active role in logistics, and thus be considered as active resources.The people that make up the crowd are a priori uncertain, and it is not possible to completely anticipate contingency plans for the unforeseen action of this communicating mass as a whole or some people (Mladenow et al., 2015). The unknown crowd identity is a significant concern (Rai et al., 2017). There is no employment contract that forces them to participate in crowd logistics processes and as such they can stop being part of the network at any moment (Jeremic \& Andrejic, 2019). Thus, for this to work effectively, it requires much trust from users for the platform. The most businessoriented businesses have adopted robust selection procedures for couriers as a way of strengthening trust (Rougès \& Montreuil, 2014). Mladenow et al., (2015) further stated that, in this situation, one only has to comply with company laws.

The influence of crowd logistics is highly dependent on the transport behavior of the crowd (Jeremic \& Andrejic, 2019). Rai et al. (2018) also mentions crowd transport behavior as a factor that determines the positive or negative environmental impact of crowd logistics. The concept encourages citizens to make use of the free capacity on a trip that was intended to be made either way (Rai et al., 2017). Alternative modes of transportation, such as motorcycles or public transportation networks, are for the choice of the crowd (Odongo, 2018). The crowd 
has the choice of delivering a package on their regular commute via public transportation or picking up their neighbors' packages and delivering them by bike or on foot (Rai et al., 2017).

In crowd logistics, sufficient compensation is key (Rai et al., 2017). In order to make crowdsourcing applications work, businesses need to understand motivational factors and offer rewards accordingly (Mladenow et al., 2015). The right rewards for the crowd are a further challenge (Mladenow et al., 2016). It is therefore important to distinguish between intrinsic and extrinsic values of motivation (Mladenow et al., 2016). In each crowdsourced process, building trust is a key success factor (Rougès \& Montreuil, 2014). Huang et al. (2020) found that trust is linked to a willingness to participate in crowd logistics in the future. In a proposition formulated by Carbone et al., (2017), the researchers stated that "The development of crowd logistics initiatives is influenced by the nature of the logistics tasks executed by the operand crowd. The easier the logistics tasks for the operand crowd, the stronger the growth of the crowd logistics initiative". In support of this, (Huang et al., 2020) mentioned that there is a significant, though very slight, adverse association between job entry barriers and continued participation.

Also, people will give up their spare time and share the potential of their extra vehicles capacity in exchange for a monetary benefit (Rai et al., 2018). There is a strong and positive correlation between monetary incentives and the desire to keep engaging in crowd logistics (Huang et al., 2020). Research by (Cieplińska \& Szmelter-Jarosz, 2020) resulted in higher weight in income, demonstrating the superiority of economic criteria over environmental and social criteria. The monetary and non-monetary referred to reflect incentives for involvement in crowdsourcing projects from the viewpoint of crowdsourcees (Horton \& Chilton, 2010).

Mladenow et al. (2015) also made it known that contributors to the European crowd-logistics companies have not only a clear financial incentive but also a social one. However, often than not the impetus to engage lies in psychological factors (Mladenow et al., 2015).

According to Mladenow et al. (2016), the processes of interactions between individuals, interpersonal aspects and consumer awareness of sustainability are given a high priority (both, the crowdsourcer and the crowdsourcee).

Regardless of whether the crowd is driven by non-monetary motivations or by the possible economic gains that can be achieved, an efficient compensation scheme is crucial for attracting participants (Odongo, 2018).

From the above reviewed literature on the concept of crowd logistics and crowd's transport behavior and for the purpose of measuring the impact of crowd logistics on environmental sustainability in Ghana, we proposed our first hypothesis below:

H1 Crowd logistics has a significant relationship with crowd's transport behavior. 


\subsection{Crowd Logistics and Environmental Sustainability}

There has been little empirical studies available on the possible financial, social, and environmental benefits of sharing economy operation in general, and crowd logistics in particular, to date (Rai et al., 2017). The key consequence of using crowd logistics is an attempt to practice a sustainable logistics system by minimizing the total number of vehicles on city streets and exploitation of empty spaces in people cars, all of which result in shorter travel distances and lower carbon emissions (Odongo, 2018). A sustainable logistics framework concentrates on logistics operations to reduce a company's costs, reduce its environmental effect, and address its social impact (Wichaisri \& Sopadang, 2013). While some researchers are presenting positive impacts, others are of the view that crowd logistics has little or no contribution to environmental sustainability depending on how it is practiced. A systematic review found that the concept's sustainability effects are highly dependent on a variety of variables (Rai et al., 2017). These dependent factors are transport behavior of the crowd, consolidation of package and crowd's modal choice (Jeremic \& Andrejic, 2019). That's by allowing clients to use low-emission vehicles, hybrid cars, motorcycles, scooters and, above all, bicycles (Huang et al., 2020). Crowd logistics has the potential to contribute to sustainable deliveries of last mile packages, but the existing use of the network by the crowd prevents the idea from achieving the desired environmental benefits (Rai et al., 2018). Some ideas rely on a base of frequent and mobile "crowd staff," while others promote dedicated trips to deliver parcels, prompting debate about crowd logistics' true capabilities to boost urban sustainability (Rai et al., 2017).

In the opinion of (Mladenow et al., 2015), delivery involvement leads to $\mathrm{CO}_{2}$ emissions reduction, because loading space would be used more effectively and traffic may be minimized as a potential result. The use of vehicle free space of individuals who are on an already planned trip will reduce pollution from unnecessary vehicle kilometers. Crowdsourced delivery enables transport resources to be best exploited by promoting the convergence and alignment of current vehicle flows, significantly reducing congestion and carbon pollution by reducing the number of vehicles required to transport goods (Sampaio, Savelsbergh et al. 2019).

Rai et al. (2018) debunked this by stating that major part of the crowd's journey is devoted to the distribution of packages, which raises its environmental impact well beyond the conventional delivery of parcels. The most successful start-ups rely mostly on experienced couriers or delivery workers, not commuters or occasional travelers (Rougès \& Montreuil, 2014). As a consequence, increase in the number of shipments and the platform's crowd network could lead to more unconsolidated and ad hoc deliveries, causing more negative environmental effects (Rai et al., 2018). Energy consumption, carbon emissions, air pollution, noise, urban mobility, and overcrowding are just a few of the effects (Rai et al., 2017). From an environmental perspective, the crowd's modal choice which favors soft modes, public transportation and environmentally friendly ve- 
hicles is also important (Rai et al., 2017). The platform provider plays a vital role in achieving environmental sustainability as his platform must encourage capacity utilization and reward crowds that exploit premeditated trips (Rai et al., 2018). This stakeholder may change the function of the network in a way that handles the optimal use of vehicle space or launches an incentive scheme that allows more packages to be shipped or decreases the number of dedicated trips (Rai et al., 2018).

The least important factor was the waste reduction and the treatment of traffic congestion and traffic avoidance, which is among the most major external transportation costs and is reported on paper in almost all transport costs (RześnyCieplińska \& Szmelter-Jarosz, 2019).

We therefore posited the following three more hypothesis based on the reviewed literature and for the purpose of determining the effect of crowd logistics on environmental sustainability in Ghana;

H2 Crowd logistics has a significant impact on environmental sustainability.

H3 Crowd's transport behavior has a positive impact on environmental sustainability.

H4 Crowd's transport behavior significantly mediates the relationship between crowd logistics and environmental sustainability.

The novelty of this study is that there is no existing literature on the concept relating to Ghana upon comprehensive search. Therefore to fill this research void, we used the descriptive survey research design to find out the stage of crowd logistics in Ghana, identify the transport behavior of the crowd and their motivational factors, and analyze the environmental sustainability effect of the concept.

\section{Research Methodology}

The methodology presented the overall steps by which the study was conducted. It focused on issues like the research design employed, the study population, the number of respondents selected from the population and how they were selected, the instruments used to collect data from respondents, how the instruments were pilot-tested to ensure validity and reliability, how the data was collected, the decision making tool used, and how it was analyzed.

In order to assess the effect of crowd logistics on the environment in Ghana, we used survey method. The research area for this study covered Accra, the capital city of Ghana. The practice of the concept is new in Ghana hence operating companies are few. One operating crowd logistics company was reached. The operators connected us to their employees, crowd, logistics service providers and receivers who are the stakeholders of the platform. The survey was done both electronically and physically.

\subsection{Sample Size}

We made use of survey-based closed ended questionnaire for the collection of 
data for this study. Sample was selected from the target population of 500 using the simple random sampling technique. The sample size for our study was determined using Yamane (1967) sample size formula:

$$
\begin{gathered}
n=\frac{N}{1+N(e)^{2}} \\
n=\frac{500}{1+500 \times(0.05)^{2}}=222.222 \sim 222
\end{gathered}
$$

where: projected sample size $(n)$, Study Population $(N)$, error parameter $(e=5 \%)$.

\subsection{Questionnaire Design}

The questionnaire was structured in four parts based on the research questions. The first part contained the basic demographic information. The first part comprising the basic information included the respondent's gender, age, occupation, qualification, type of stakeholder, and experience in crowd logistics. The second part assessed the level of crowd logistics in Ghana. The third part analyzed the transport behavior of the crowd. The Fourth part assessed the impact of crowd logistics on environmental sustainability in Ghana. A 7-point Likert scale was used to quantify the variables in our study: 1 = "strongly disagree", 2 = "disagree" 3 = "moderately disagree", $4=$ "neutral", 5 = "moderately agree", $6=$ "agree", and 7 = "strongly agree". The questionnaire for this study was adapted from (Rześny-Cieplińska and Szmelter-Jarosz, 2019; Huang, Xie et al. 2020) and modified to fit this current study. Precisly, the criterion for the variables of the questionnaire were adapted and structured into items.

\subsection{Data Collection}

The methodological procedure for data collection for this study which included online and offline, had the online questionnaire designed using google forms, and sent through emails and WhatsApp to respondents who are at a distant. The offline questionnaires were printed and distributed to respondent who were physically reached. In total, 222 questionnaires were distributed. Recovery rate is $100 \%$.

\subsection{Research Model}

The research model for this study shows the direct relationship between the independent variable (crowd logistics practice) and the dependent variable (environmental sustainability). It also shows the mediating roles of crowd's transport behavior between crowd logistics practice and environmental sustainability as shown in Figure 1.

\section{Result and Discussion}

The data analysis in this study was carried out with AMOS 24 and SPSS 25. 


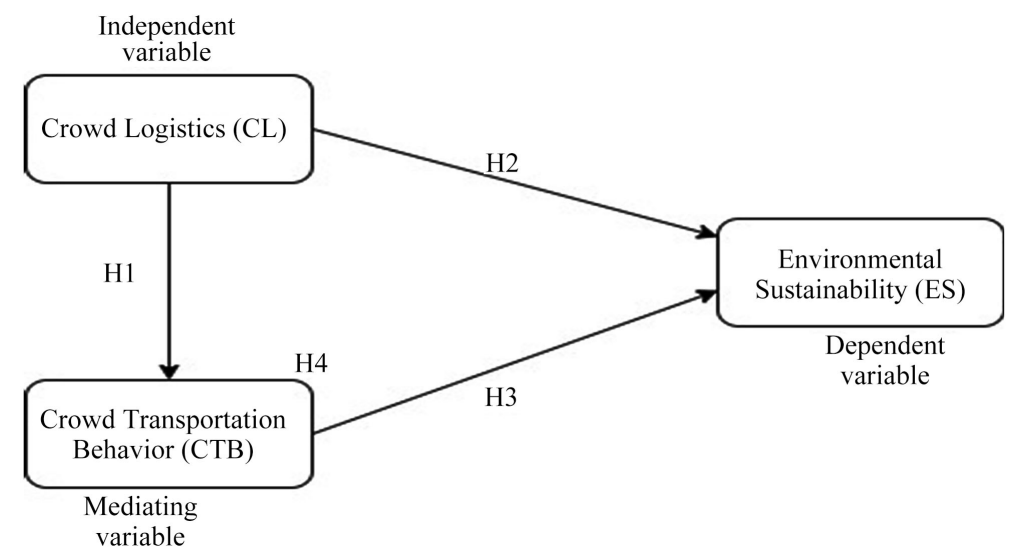

Figure 1. Research model.

Structural Equation Modeling (SEM) and Bootstrapping (Sobel test) analysis were used to examine the relationships between the variables as presented in the proposed hypotheses. According to Kumar \& Nambirajan, (2013) most often, researchers in supply chains usually employed the use of SEM analysis and technique in data analysis and interpretations. Ganiyu et al., (2020) posited that analysis involving SEM entails modeling an event using both latent and manifest variables to characterize the event. The results of the data analysis are presented below:

\section{Descriptive Characteristics of Respondents}

Table 1 presents the descriptive characteristics of our respondents. According to the results obtained, most of our respondents were male, and they account for $58.1 \%$, while $41.9 \%$ were females. Result also indicated that $33.8 \%$ of our respondents were between the ages of $18-30,31.1 \%$ between the ages of $31-40$, $18.0 \%$ between the ages of $41-50,10.4 \%$ between the ages of $51-60$ and $6.8 \%$ are above 60 years. Most of these respondents are graduates, and they account for $43.2 \%$, followed by WASSCE/SSCE educational level accounting for $24.8 \%$ and then the respondents who are Post-graduates and Doctorate accounting for $22.1 \%$ and $9.9 \%$ respectively. $31.1 \%$ of our respondents have experienced the practice for less than a year, $36.9 \%$ for $1-3$ years, while $18.5 \%$ and $13.5 \%$ have worked for 3 - 5 years and above 5 years respectively. Among the respondents, $31.1 \%$ are employees and platform providers, $22.1 \%$ are the crowd, $16.2 \%$ are receivers, $19.8 \%$ are logistics players, $9.5 \%$ are commissioners and $1.4 \%$ are other participants

The correlation analysis presented in Table 2 shows significant relationship between our variables. The result indicates moderate associations between our variables (Mukaka, 2012). We performed the correlation analysis using Pearson coefficient to determine the magnitude, direction and significance of the relationships that exist between the variables in our model (Wackerly et al., 2008; Rodgers \& Nicewander, 1998). Yoo et al., (2014) posited that correlation estimates of 0.80 and above may be concerns for multicollinearity. As presented in 
Table 2, the estimated correlation coefficients ranged from $0.767-0.777$ indicating that concerns of multicollinearity may not be an issue in our model. The diagonal estimates in bold are the square root of the Average Variance Extracted (AVE) for each of the latent construct used to assess the discriminant validity of our model.

A collinearity diagnostics test was also performed to examine the presence of Table 1. Descriptive profile of respondents.

\begin{tabular}{|c|c|c|c|c|}
\hline Demographic Characteristic & Frequency & Percent & Valid Percent & Cumulative Percent \\
\hline \multicolumn{5}{|l|}{ Gender } \\
\hline Male & 129 & 58.1 & 58.1 & 58.1 \\
\hline Female & 93 & 41.9 & 41.9 & 100.0 \\
\hline Total & 222 & 100.0 & 100.0 & \\
\hline \multicolumn{5}{|l|}{ Educational Background } \\
\hline WASSCE/SSCE & 55 & 24.8 & 24.8 & 24.8 \\
\hline Bachelors & 96 & 43.2 & 43.2 & 68.0 \\
\hline Masters & 49 & 22.1 & 22.1 & 90.1 \\
\hline Doctorate & 22 & 9.9 & 9.9 & 100.0 \\
\hline Total & 222 & 100.0 & 100.0 & \\
\hline \multicolumn{5}{|l|}{ Age } \\
\hline $18-30$ & 75 & 33.8 & 33.8 & 33.8 \\
\hline $31-40$ & 69 & 31.1 & 31.1 & 64.9 \\
\hline $41-50$ & 40 & 18.0 & 18.0 & 82.9 \\
\hline $51-60$ & 23 & 10.4 & 10.4 & 93.2 \\
\hline 61 and above & 15 & 6.8 & 6.8 & 100.0 \\
\hline Total & 222 & 100.0 & 100.0 & \\
\hline \multicolumn{5}{|l|}{ Job Experience } \\
\hline Less than one year & 69 & 31.1 & 31.1 & 31.1 \\
\hline $1-3$ year(s) & 82 & 36.9 & 36.9 & 68.0 \\
\hline $3-5$ years & 41 & 18.5 & 18.5 & 86.5 \\
\hline 6 years and above & 30 & 13.5 & 13.5 & 100.0 \\
\hline Total & 222 & 100.00 & 100.00 & \\
\hline \multicolumn{5}{|l|}{ Company Relationship } \\
\hline Employee/Platform Provider & 69 & 31.1 & 31.1 & 31.1 \\
\hline Crowd & 49 & 22.1 & 22.1 & 53.2 \\
\hline Receiver & 36 & 16.2 & 16.2 & 69.4 \\
\hline Logistics Player & 44 & 19.8 & 19.8 & 89.2 \\
\hline Commissioner & 21 & 9.5 & 9.5 & 98.6 \\
\hline Other & 3 & 1.4 & 1.4 & 100.0 \\
\hline Total & 222 & 100.0 & & \\
\hline
\end{tabular}


Table 2. Correlation matrix.

\begin{tabular}{ccccccc}
\hline \multirow{2}{*}{ Variable } & \multicolumn{5}{c}{ Correlation Matrix } \\
\cline { 2 - 7 } & Mean & Std. Dev & Cronbach's a & 1 & 2 & 3 \\
\hline CL & 26.03 & 8.67 & 0.897 & 0.779 & & \\
CTB & 27.05 & 8.52 & 0.930 & $0.777^{* *}$ & 0.823 & \\
ES & 22.20 & 7.53 & 0.923 & $0.767^{* *}$ & $0.771^{* *}$ & 0.856 \\
\hline
\end{tabular}

*** Correlation is significant at the 0.01 level (2-tailed) and square root of AVE in the diagonals.

multicollinearity and autocorrelation in our model. Results presented in Table 3 indicates that the estimated values of Tolerance and VIF are within the acceptable values (VIF $<5$, Tolerance $>0.10$ ) as suggested by (Daoud, 2017; Ringle et al., 2015). The Durbin-Watson estimate was 2.097 which implies moderate and acceptable autocorrelation in our model (Field, 2009). This results further implies the absence of multicollinearity and autocorrelation in our model.

Table 4 and Figure 2 presents the results for the structural model. Figure 2 presents the factor loadings of each observed variable to the latent construct. The estimated factor loadings are all above the minimum threshold of 0.60 suggested by Hair et al., (2006), McNallie, 2020. The standardized item loadings shown in Table 4 are all statistical significant with $\mathrm{P}$-values less than $0.001(P<0.001$, two-tailed) and T-values estimated are all higher than $1.96\left(t_{\text {cal }}>t_{\text {critical }}\right)$. The results above indicates that the observed items load satisfactorily.

The degree that the structural equation model (SEM) fits the measured data is referred to as model fit. The objective of model fitting evaluation is to validate the theoretical model using the fitting parameters technique (Ganiyu et al., 2020). The model fitting parameters commonly reported by most researchers include the following: CFI, TLI, GFI, NFI, RMSEA and SRMR. According to Kline (2005), model fit should be evaluated using at least one of the following indices: $\chi^{2}$-ratio, RMSEA, CFI, and SRMR. The threshold criteria for SEM fitting indices are recommended by (Hooper et al., 2008; Kline, 2005; Steiger, 2007; Wen et al., 2004; Burnham \& Anderson, 2002; Hoyle \& Panter, 1995). They believe that a Chisquare ratio ( $\chi^{2}$-ratio) of less than 3 indicates a model that is reasonable and can be accepted. But then, this particular fit parameter is not always regarded as a reliable model fit evaluation index (Bwaliez \& Abushaikha, 2019). TLI should be greater than 0.95 (TLI $>0.95$ ), but TLI $>0.90$ suggests a reasonable model fit. For a good model fit, CFI should be above 0.90 (CFI $>0.90$ ). For a satisfactory model fit to be achieved, both RMSEA and SRMR should be less than 0.05 (RMSEA $<0.05$, SRMR $<0.05$ ), and for an appropriate model fit, they should be less than 0.08 (RMSEA $<0.08$, SRMR $<0.08$ ). For a reasonable model fit, GFI and NFI must both be above 0.95 (GFI, NFI > 0.95). The results presented in Table 5 indicates that structural model fits the data satisfactorily since all the fit measures are established. 


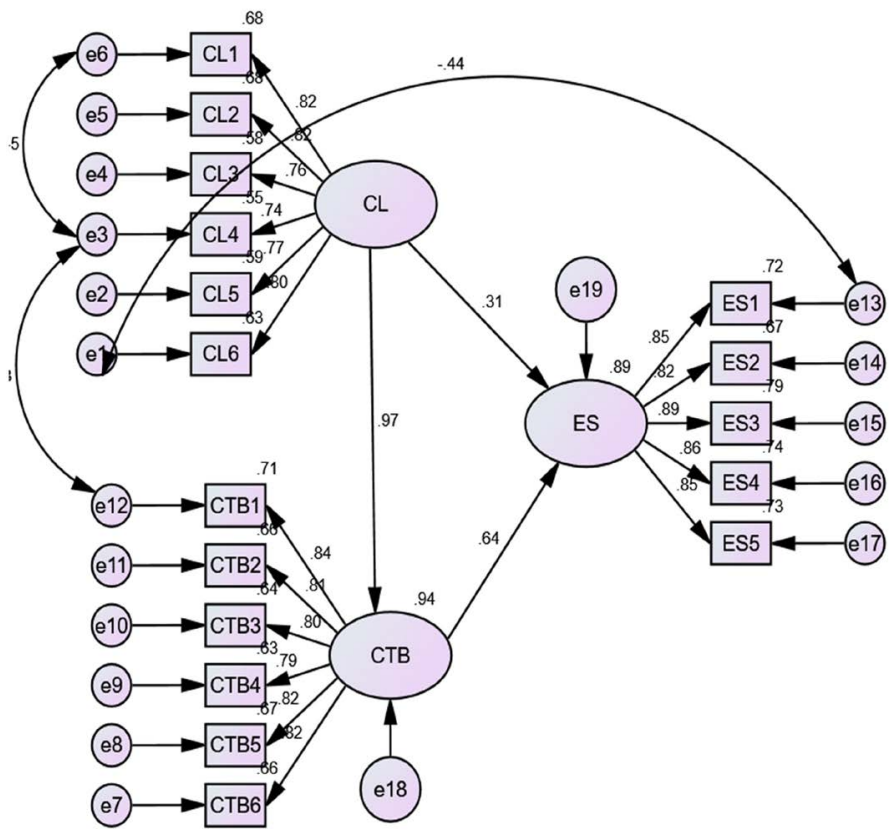

Figure 2. Structural model.

Table 3. Collinearity diagnostics.

\begin{tabular}{cccc}
\hline Variable & Tolerance & VIF & Durbin-Watson \\
\hline CL & 0.231 & 4.334 & \\
CTB & 0.231 & 4.334 & 2.097 \\
\hline
\end{tabular}

Table 4. Structural model results.

\begin{tabular}{cccccccc}
\hline $\begin{array}{c}\text { Latent } \\
\text { Variable }\end{array}$ & Item & $\begin{array}{c}\text { Regression } \\
\text { Weights }\end{array}$ & $\begin{array}{c}\text { Standard } \\
\text { Error (SE) }\end{array}$ & T-Value & $\begin{array}{c}\text { Average } \\
\text { Variance } \\
\text { Extracted (AVE) }\end{array}$ & $\begin{array}{c}\text { Composite } \\
\text { Reliability } \\
\text { (CR) }\end{array}$ & $\begin{array}{c}\text { Standa } \\
\text { rdized Factor } \\
\text { Loading }\end{array}$ \\
\hline & CL1 & 0.983 & 0.066 & 14.903 & & & 0.824 \\
& CL2 & 1 & - & - & & & 0.825 \\
\hline CL & CL3 & 0.895 & 0.067 & 13.290 & & & 0.759 \\
\hline & CL4 & 0.935 & 0.073 & 12.788 & 0.620 & 0.907 & 0.744 \\
& CL5 & 0.911 & 0.067 & 13.611 & & & 0.771 \\
& CL6 & 0.929 & 0.065 & 14.283 & & & 0.796 \\
& CTB1 & 1 & - & - & & 0.843 \\
& CTB2 & 0.968 & 0.064 & 15.027 & & 0.810 \\
\hline CTB & CTB3 & 0.967 & 0.065 & 14.792 & & & 0.802 \\
\hline & CTB4 & 0.976 & 0.067 & 14.560 & 0.662 & 0.922 & 0.794 \\
& CTB5 & 0.930 & 0.061 & 15.281 & & & 0.818 \\
& CTB6 & 0.926 & 0.061 & 15.190 & & & 0.815 \\
& ES1 & 0.919 & 0.052 & 17.646 & & & 0.847 \\
& ES2 & 0.864 & 0.052 & 16.580 & & 0.821 \\
\hline ES & ES3 & 1 & - & - & 0.728 & 0.930 & 0.886 \\
\hline ES4 & 0.896 & 0.049 & 18.130 & & & 0.859 \\
& ES5 & 0.898 & 0.050 & 17.824 & & & \\
\hline
\end{tabular}


Table 5. Model fit.

\begin{tabular}{ccccccccc}
\hline Fit index & $\chi^{2} / \mathrm{df}$ & RMSEA & SRMR & GFI & TLI & CFI & NFI & RFI \\
\hline Recommended value & $<5$ & $<0.06$ & $<0.08$ & $>0.95$ & $>0.95$ & $>0.9$ & $>0.95$ & $>0.9$ \\
Estimated value & 2.148 & 0.042 & 0.056 & 0.962 & 0.945 & 0.904 & 0.955 & 0.928 \\
\hline
\end{tabular}

\section{Reliability and Validity}

The internal accuracy of scale items is measured by Cronbach's alpha and the Composite reliability test statistics (Spiliotopoulou, 2009; Netemeyer et al., 2003). The reliability of the questionnaire used in this analysis was measured using these test statistics. Devon et al., (2007) indicated that, Cronbach's alpha is the preferred method for measuring internal accuracy of questionnaire. Fornell \& Lacker (1981) and Hair et al., (2010) suggested a minimum Composite reliability value of 0.70 and 0.60 respectively while Bland \& Altman (1997) proposed a minimum Cronbach's value of 0.70 . These estimates are required for determining the reliability of our survey questionnaire. The results presented in Table 2 shows all estimated Cronbach's alpha and Composite reliabilities to be accepted (CA $=0.897$ - 0.930, CR $=0.907-0.930$ ).

The validity of the estimated structural model was achieved using Composite reliability and Average Variance Extracted (AVE) measures (Bagozzi \& Yi, 1998; Fornell \& Lacker, 1981). The validity of the structural model was estimated based on convergent validity and discriminant validity, collectively referred to as construct validity (Gregory, 2007; Hubley \& Zumbo, 1996). Chin \& Yao, (2014) posited that convergent validity measures convergence between similar measurement items and it is measured by using the AVE estimates. AVE value of 0.50 indicates that convergent validity has been achieved. Table 4 presents that all estimated AVE values are above the minimum threshold for establishment of convergent validity (AVE $=0.620-0.728)$.

The discriminant validity of the structural model was estimated using the approach proposed by Fornell \& Lacker, (1981). They asserted that, discriminant validity criterion is satisfied if the square root of AVE for each latent construct is larger than the inter-construct correlation coefficients. The results tabulated in Table 2 presents that the square root of the AVE values are larger than the estimated inter-construct correlation coefficients, hence discriminant validity criterion was satisfied. This further implies that, the construct validity for the structural model was achieved.

The results presented in Table 6 revealed a significant association between Crowd Logistics (CL) and Crowd Transport Behavior (CTB). The estimated path coefficient between CL and CTB was 0.972 , indicating a positive significant relationship between CL on CTB. This further revealed the influence of the transport behavior of the crowd on CL. Jeremic \& Andrejic, (2019) presented the major role that CL plays in transport behavior of crowd. They concluded that, the impact of crowd logistics is highly dependent on the crowd's mobility attitude. 
Table 6. Hypothesis testing and decision.

\begin{tabular}{|c|c|c|c|c|c|c|}
\hline Hypothesis & Relationship & Path Estimates & SE & $t$-value & $p$-value & Hypothesis Decision \\
\hline $\mathrm{H} 1$ & CL CTB & 0.972 & 0.062 & 14.909 & $* * *$ & Supported \\
\hline $\mathrm{H} 2$ & CL ES & 0.312 & 0.135 & 2.311 & $* * *$ & Supported \\
\hline H3 & CTB ES & 0.639 & 0.311 & 2.306 & 0.021 & Supported \\
\hline \multicolumn{7}{|c|}{ Bootstrap Analysis of Indirect Effect of CL } \\
\hline & & Estimate & SE & LLCI & ULCI & \\
\hline $\mathrm{H} 4$ & $\left(\mathrm{CL}^{*} \mathrm{CTB}\right) \mathrm{ES}$ & 0.365 & 0.064 & 0.227 & 0.495 & Supported \\
\hline
\end{tabular}

The relationship between Crowd Logistics (CL) and Environmental Sustainability (ES) was statistically significant with a path estimate of 0.312 . This relationship was statistically significant with a $P$-value of $0.000(P<0.05)$ and a T-ratio of 2.311 ( $\mathrm{T}>1.96$ ). The implication of this results is that, crowd logistics activities tend to protect the environment hence ensuring sustainability of the environment (Mladenow et al., 2015; Sampaio et al., 2019).

Crowd Transport Behavior (CTB) was found to impact positively on Environmental Sustainability (ES) with a path estimate of 0.639 . The estimated path relationship was statistically significant with a $P$-value of $0.021(P<0.05)$. The significant positive association between CTB and ES reveals that crowd movement attitude or behavior may have a positive influence on sustainability of the environment.

To determine the estimate and statistical significance of the indirect effect of CL on ES through the intermediary variable CTB, we used the Bootstrap approach (Preacher \& Hayes, 2004) to estimating and testing the indirect or mediation effect. Researchers advocate the use of this approach to testing the statistical significance of indirect effects because it does not assume any level of normality and it adequately estimate confidence level based on simulated distributions. The result is presented in Table 6 and indicates that, the indirect effect size is 0.365 with a standard error of 0.064 . This indirect effect is statistically significant at the 95\% confidence level. The Lower Level Confidence Interval (LLCI) is estimated to be 0.227 and the Upper Level Confidence Interval is estimated to be 0.495 , indicating statistical significance since zero (0) lies outside the Lower and Upper level confidence regions. Therefore we accept our hypothesis four (H4) and conclude that, Crowd Transport Behavior (CTB) significantly mediates the relationship between Crowd Logistics (CL) and Environmental Sustainability (ES). The results presented in Table 6 indicates the acceptance of all the four hypotheses $(\mathrm{H} 1, \mathrm{H} 2, \mathrm{H} 3$ and $\mathrm{H} 4)$ proposed in this study.

\section{Conclusion}

The goal of this study is to indicate if CL concept can impact environmental sustainability. Our research concludes with findings that show support for all four hypotheses we proposed, according to a comprehensive and accurate quantita- 
tive data collection (Questionnaire) and analysis.

Crowd's transport behavior has a significant positive relationship with crowd logistics, which supports our first hypothesis. The mode of transportation (biking, walking, clean fuel vehicle and using public transportation), planned trip (not for delivery purposes), delivery by regular people rather than professional drivers and not undertaking additional trips for delivery purposes have a positive impact on the main goal of crowd logistics. More than half of our respondents accepted that crowds use environmentally sustainable forms of transportation to deliver goods, which helps with sustainability. Our results backed up the third hypothesis, which notes that crowd transportation activity has a positive relationship with environmental sustainability as well. The majority of our respondents, on the other hand, agreed with the statement that deliveries are made by professional drivers who work for delivery companies but have spare capacity. This contradicts the true intent of crowd logistics, implying that the crowd consists of committed drivers rather than passengers who are on already planned journey. The environmental sustainability capability of crowd logistics is therefore determined by the crowd's mobility decisions and attitude. The negative environmental effect of dedicated parcel deliveries by crowd is much greater than the impact of traditional parcel deliveries (Rai et al., 2018).

Our findings also confirmed our second hypothesis, that crowd logistics has a positive relationship with environmental sustainability. By implementing crowd logistics, companies can serve their customers in an environmentally friendly manner (Mladenow et al., 2015). The items that state that crowd logistics eliminates carbon emissions, noise, injuries, pollution, and physical waste into the atmosphere earned a higher percentage of our respondents' support. Crowd logistics has the ability to support the environment, but the authenticity and behavior of the crowd inhibits it. This finding concurs with existing research that shows crowd logistics has a positive impact on the environment.

Crowd's transport behavior is a significant means by which crowd logistics impacts environmental sustainability. Our findings validated this final hypothesis. Crowd's transport behavior therefore appears as a necessary mediator between CL and environmental sustainability. The crowd is critical for crowd logistics to achieve its goal of environmental sustainability. Our results demonstrate that the crowd is both intrinsically and extrinsically driven. Financial compensation is equally as important as the desire to experience new things. In order to create an incentivization scheme for the crowd, many reward structures must be integrated (Blohm et al., 2018). In addition to monetary benefit, the crowd must recognize the environmental benefit associated with the concept's successful implementation. The key incentive of the crowd is also important in the case of environmental impacts of Crowd logistics (Rai et al., 2017). The health benefits that their effective participation provides to society should be intrinsically motivating for this stakeholder. Despite the fact that there is some literature on the sustainability side of crowd logistics, there isn't enough research on the impact of crowd transport behavior on crowd logistics and environmental sustai- 
nability.

Our research also found that in Ghana, crowd logistics is still in its early stages of development. The general public does not have access to adequate knowledge about the concept. The efficient implementation of Crowd logistics is hampered by factors such as the economic system, low IT consumption, and modes of transportation. Regardless, people are still willing to accept and participate in the concept's implementation.

\section{Implication of the Study}

Our findings complement existing literature by providing insight on the role of the crowd in the practice of crowd logistics to achieve environmental sustainability. It creates awareness as to how the efficient involvement of the crowd in crowd logistics is necessary for sustainable development. The findings of this study can be used to provide important realization not only to CL practitioners and local authorities, but also to policymakers who are responsible for sustainable development. Policymakers can use this to make policies that ensure efficient transport behavior from the crowd in order to achieve environmental sustainability. Information provided by this study can serve as a reference point to decision makings regarding sustainable mobility of crowd. It can also be a basis for investment decision making.

\section{Limitation and Future Research}

The current study has some limitations, which could provide some possible directions for future studies. The fact that Ghana was chosen as the survey background poses a drawback because it restricts the generalization of the study's findings. Ghana's economic outlook is optimistic but still developing, with GDP growth of $6.1 \%$ in 2019 and $1.5 \%$ in 2020 due to COVID-19 (World Bank, 2020). Ghana's status as a developing economy could build certain barriers to the findings' generalization from a more sustainable perspective. This is because, as a developing economy, it is still grappling with issues such as transportation, digitization, and policy implementation. However, due to a number of significant advantages it has over other countries in the region in terms of geography, institutions and human resources, Ghana could be the first to kick-start West Africa's industrialization process (Smith, 2020). Our research adds to the literature on crowd logistics by extending the scope of crowd logistics to include developing and emerging economies. In order to gain more body of research, future studies on the topic should focus on analyzing other factors that determine whether crowd logistics has a positive or negative environmental impact and the effect of other stakeholders on crowd logistics and environmental sustainability.

\section{Conflicts of Interest}

The authors declare no conflicts of interest regarding the publication of this paper. 


\section{References}

Ansah, R. K., Obiri-Yeboah, K., \& Akipelu, G. (2020). Improving the Freight Transport of a Developing Economy: A Case of Boankra Inland Port. Journal of Shipping and Trade, 5, 1-22. https://doi.org/10.3390/su2010252

Armah, F. A., Yawson, D. O., \& Pappoe, A. A. (2010). A Systems Dynamics Approach to Explore Traffic Congestion and Air Pollution Link in the City of Accra, Ghana. Sustainability, 2, 252-265.

Bagozzi, R. P., \& Yi, Y. (1998). On the Evaluation of Structure Equation Models. Journal of the Academy of Marketing Science, 16, 76-94.

Bland, J. M., \& Altman, D. G. (1997). Statistics Notes: Cronbach's Alpha. BMJ, 314, 572. https://doi.org/10.1136/bmj.314.7080.572

Blohm, I., Zogaj, S., Bretschneider, U., \& Leimeister, J. M. (2018). How to Manage Crowdsourcing Platforms Effectively? California Management Review, 60, 122-149. https://doi.org/10.1177/0008125617738255

Burnham, K. P., \& Anderson, D. R. (2002). Model Selection and Inference: A Practical Information-Theoretical Approach (2nd ed.). New York: Springer.

Bwaliez, O. M., \& Abushaikha, I. (2019). Integrating the SRM and Lean Paradigms: The Constructs and Measurements. Theoretical Economics Letters, 9, 2371-2396. https://doi.org/10.4236/tel.2019.97151

Carbone, V., Rouquet, A., \& Roussat, C. (2017). The Rise of Crowd Logistics: A New Way to Co-Create Logistics Value. Journal of Business Logistics, 38, 238-252. https://doi.org/10.1111/jbl.12164

Chin, C. L., \& Yao, G. (2014). Convergent Validity. In A. C. Michalos (Ed.), Encyclopedia of Quality of Life and Well-Being Research. Dordrecht: Springer. https://doi.org/10.1007/978-94-007-0753-5 573

Cieplińska, J. R., \& Szmelter-Jarosz, A. (2020). Toward Most Valuable City Logistics Initiatives: Crowd Logistics Solutions' Assessment Model. Central European Management Journal, 28, 38-56. https://doi.org/10.7206/cemj.2658-0845.21

Dadzie, K. Q., Winston, E., \& Hinson, R. (2015). Competing with Marketing Channels and Logistics in Africa's Booming Markets: An Investigation of Emerging Supply Chain Management Practices in Ghana. Journal of Marketing Channels, 22, 137-152. https://doi.org/10.1080/1046669X.2015.1018079

Daoud, J. I. (2017). Multicollinearity and Regression Analysis. Journal of Physics: Conference Series, 949, Article ID: 012009. https://doi.org/10.1088/1742-6596/949/1/012009

Devon, H. A., Block, M. E., Moyle-Wright, P., Ernst, D. M., Hayden, S. J., Lazzara, D. J., Savoy, S. M., \& Kostas-Polston, E. (2007). A Psychometric Toolbox for Testing Validity and Reliability. Journal of Nursing Scholarship, 39, 155-164. https://doi.org/10.1111/j.1547-5069.2007.00161.x

El-Berishy, N., Rügge, I., \& Scholz-Reiter, B. (2013). The Interrelation between Sustainability and Green Logistics. IFAC Proceedings Volumes, 46, 527-531. https://doi.org/10.3182/20130911-3-BR-3021.00067

Esmizadeh, Y., \& Mellat Parast, M. (2021). Logistics and Supply Chain Network Designs: Incorporating Competitive Priorities and Disruption Risk Management Perspectives. International Journal of Logistics Research and Applications, 24, 174-197. https://doi.org/10.1080/13675567.2020.1744546

Field, A. P. (2009). Discovering Statistics Using SPSS for Windows: Advanced Techniques for the Beginner (3rd ed.). London: Sage.

Fornell, C., \& Larcker, D. (1981). Structural Equation Models with Unobservable Va- 
riables and Measurement Error: Algebra and Statistics. Journal of Marketing Research, 18, 382-388. https://doi.org/10.1177/002224378101800313

Ganiyu, S., Yu, D., Xu, C., \& Providence, A. (2020). The Impact of Supply Chain Risks and Supply Chain Risk Management Strategies on Enterprise Performance in Ghana. Open Journal of Business and Management, 8, 1491-1507. https://doi.org/10.4236/ojbm.2020.84095

Gregory, R. J. (2007). Psychology Testing: History, Principles and Application (5th ed.). Boston, MA: Ally \& Bacon.

Hair Jr., Black, J. F., Babin, W. C., Anderson, R. E., \& Tatham, R. L. (2006). Multivariate Data Analysis (6th ed.). Upper Saddle River, NJ: Pearson-Prentice Hall.

Hair, J. F., Black, W. C., Babin, B. J., \& Anderson, R. E. (2010). Multivariate Data Analysis (7th ed.). Upper Saddle River, NJ: Prentice Hall.

Herrmann, E., \& Kunze, O. (2019). Facility Location Problems in City Crowd Logistics. Transportation Research Procedia, 41, 117-134.

https://doi.org/10.1016/j.trpro.2019.09.023

Hooper, D., Coughlan, J., \& Mullen, M. R. (2008). Equation Modelling: Guidelines for Determining Model Fit. Electronic Journal of Business Research Methods, 6, 53-60.

Horton, J. J., \& Chilton, L. B. (2010). The Labor Economics of Paid Crowdsourcing. Proceedings of the 11th ACM Conference on Electronic Commerce, Cambridge, 7-11 June 2010, 209-218. https://doi.org/10.1145/1807342.1807376

Howe, J. (2008). Crowdsourcing: How the Power of the Crowd Is Driving the Future of Business. New York: Random House.

Hoyle, R. H., \& Panter, A. T. (1995). Writing about Structural Equation Modeling. In R. H. Hoyle (Ed.), Structural Equation Modelling (pp. 158-176). Thousand Oaks, CA: Sage.

Huang, L., Xie, G., Blenkinsopp, J., Huang, R., \& Bin, H. (2020). Crowdsourcing for Sustainable Urban Logistics: Exploring the Factors Influencing Crowd Workers' Participative Behavior. Sustainability, 12, 3091. https://doi.org/10.3390/su12083091

Hubley, A. M., \& Zumbo, B. D. (1996). A Dialectic on Validity: Where We Have Been and Where We Are Going. The Journal of General Psychology, 123, 207-215. https://doi.org/10.1080/00221309.1996.9921273

Islam, D. M. Z., Meier, J. F., Aditjandra, P. T., Zunder, T. H., \& Pace, G. (2013). Logistics and Supply Chain Management. Research in Transportation Economics, 41, 3-16. https://doi.org/10.1016/j.retrec.2012.10.006

Jeremic, M., \& Andrejic, M. (2019). Crowd Logistics-A New Concept in Realisation of Logistics Services. 4th Logistics International Conference, Belgrade, 23-25 May 2019, 170-179.

Kline, R. B. (2005). Principles and Practice of Structural Equation Modeling (2nd ed.). New York: Guilford.

Kumar, C., \& Nambirajan, T. (2013). An Integrated Model for Supply Chain Management Components, Supply Chain Performance and Organizational Performance: Purification and Validation of a Measurement Instrument. The Journal of Contemporary Management Research, 8, 37-56.

McNallie, J. (2020). Structural Equation Modeling. The International Encyclopedia of Media Psychology, 1-6. https://doi.org/10.1002/9781119011071.iemp0044

Mehmann, J., Frehe, V., \& Teuteberg, F. (2015). Crowd Logistics-A Literature Review and Maturity Model. In Innovations and Strategies for Logistics and Supply Chains: Technologies, Business Models and Risk Management. Proceedings of the Hamburg 
International Conference of Logistics (HICL) (Vol. 20, pp. 117-145). Berlin: Epubli $\mathrm{GmbH}$.

Mladenow, A., Bauer, C., \& Strauss, C. (2015). Crowdsourcing in Logistics: Concepts and Applications Using the Social Crowd. Proceedings of the 17th International Conference on Information Integration and Web-Based Applications \& Services, Brussels, 11-13 December 2015, 1-8. https://doi.org/10.1145/2837185.2837242

Mladenow, A., Bauer, C., \& Strauss, C. (2016). "Crowd Logistics": The Contribution of Social Crowds in Logistics Activities. International Journal of Web Information Systems, 12, 379-396. https://doi.org/10.1108/IJWIS-04-2016-0020

Mukaka, M. M. (2012). Statistics Corner: A Guide to Appropriate Use of Correlation Coefficient in Medical Research. Malawi Medical Journal, 24, 69-71.

Netemeyer, R. G., Bearden, W. O., \& Sharma, S. (2003). Scaling Procedures: Issues and Applications. Thousand Oaks, CA: SAGE. https://doi.org/10.4135/9781412985772

Obeng-Odoom, F. (2010). Drive Left, Look Right: The Political Economy of Urban Transport in Ghana. International Journal of Urban Sustainable Development, 1, 33-48. https://doi.org/10.1080/19463130903561475

Odongo, B. (2018). How Crowd Sourcing Is Changing the Face of Last Mile Delivery: Crowd Logistics.

Preacher, K. J., \& Hayes, A. F. (2004). SPSS and SAS Procedures for Estimating Indirect Effects in Simple Mediation Models. Behavior Research Methods, Instruments, \& Computers, 36, 717-731. https://doi.org/10.3758/BF03206553

Rai, H. B., Verlinde, S., \& Macharis, C. (2018). Shipping outside the Box. Environmental Impact and Stakeholder Analysis of a Crowd Logistics Platform in Belgium. Journal of Cleaner Production, 202, 806-816. https://doi.org/10.1016/j.jclepro.2018.08.210

Rai, H. B., Verlinde, S., Merckx, J., \& Macharis, C. (2017). Crowd Logistics: An Opportunity for More Sustainable Urban Freight Transport? European Transport Research Review, 9, 1-13. https://doi.org/10.1007/s12544-017-0256-6

Ringle, C. M., Wende, S., \& Becker, J.-M. (2015). SmartPLS 3. Bönningstedt: SmartPLS. http://www.smartpls.com

Rodgers, J. L., \& Nicewander, W. A. (1988). Thirteen Ways to Look at the Correlation Coefficient. The American Statistician, 42, 59-66. https://doi.org/10.2307/2685263

Rougès, J. F., \& Montreuil, B. (2014). Crowdsourcing Delivery: New Interconnected Business Models to Reinvent Delivery. 1st International Physical Internet Conference, Vol. 1, 1-19.

Rześny-Cieplińska, J., \& Szmelter-Jarosz, A. (2019). Assessment of the Crowd Logistics Solutions-The Stakeholders' Analysis Approach. Sustainability, 11, 5361. https://doi.org/10.3390/su11195361

Sampaio, A., Savelsbergh, M., Veelenturf, L., \& Van Woensel, T. (2019). Crowd-Based City Logistics. In Sustainable Transportation and Smart Logistics (pp. 381-400). Amsterdam: Elsevier. https://doi.org/10.1016/B978-0-12-814242-4.00015-6

Sarbah, A., Fokouh, S. K., Obeng, E., \& Quaye, I. (2014). Managing City Logistics in Ghana' Trends, Developments and Its Implications to City Dwellers. International Journal of Commerce and Management, 2, 1-34.

Smith, N. (2020). Why Ghana Is Africa's Top Candidate for Economic Leap. https://www.bloomberg.com/opinion/articles/2020-02-10/ghana-is-africa-s-top-candid ate-for-economic-development

Spiliotopoulou, G (2009). Reliability Reconsidered: Cronbach's Alpha and Paediatric Assessment in Occupational Therapy. Australian Occupational Therapy Journal, 56, 150-155. https://doi.org/10.1111/j.1440-1630.2009.00785.x 
Steiger, J. H. (2007). Understanding the Limitations of Global Fit Assessment in Structural Equation Modeling. Personality and Individual Differences, 42, 893-898. https://doi.org/10.1016/j.paid.2006.09.017

Szmelter-Jarosz, A., \& Rześny-Cieplińska, J. (2020). Priorities of Urban Transport System Stakeholders According to Crowd Logistics Solutions in City Areas. A Sustainability Perspective. Sustainability, 12, 317. https://doi.org/10.3390/su12010317

Wackerly, D. D., Mendenhall III, W., \& Scheaffer, R. L. (2008). Multivariate Probability Distributions. In Mathematical Statistics with Applications (7th ed., pp. 223-295). Belmont, CA: Brooks/Cole.

Wen, Z. L., Hau, K. T., \& Marsh, H. W. (2004). Structural Equation Model Testing: Cutoff Criteria for Goodness of Fit and Chi Square. Acta Psychologica Sinica, 36, 186-194.

Wichaisri, S., \& Sopadang, A. (2013). Sustainable Logistics System: A Framework and Case Study. 2013 IEEE International Conference on Industrial Engineering and Engineering Management, Bangkok, 10-13 December 2013, 1017-1021. https://doi.org/10.1109/IEEM.2013.6962564

World Bank (2020). The Worldbank in Ghana. https://www.worldbank.org/en/country/ghana/overview

Yamane, T. (1967). Statistics, an Introductory Analysis (2nd ed.). New York: Harper and Row.

Yoo, W., Mayberry, R., Bae, S., Singh, K., He, Q. P., \& Lillard, J. W. Jr. (2014). A Study of Effects of Multicollinearity in the Multivariate Analysis. International Journal of Applied Science and Technology, 4, 9-19. 